\title{
An Overview of Translation Science
}

\author{
Andreja Radetič
}

\author{
Šolski center Krško-Sevnica, CKŽ 131, 8270 Krško, Slovenia, EU \\ andreja.radetic@gmil.com
}

\begin{abstract}
The article attempts to present basic terms, used in translation science. It explains the types and forms of translation and differences between translating and interpreting. Types of interpreting are also named. Some organizations, which deal with translating, are enumerated. The article also explains what is translatability and skims through the history and branches of translation science.
\end{abstract}

Keywords-interpreting, translating, translatability, translation science

\section{INTRODUCTION}

In the globalized world none of us can escape the necessity of a text being translated into a foreign or mother tongue. Translators and interpreters play a huge role in making this happen. However, it is of vital importance that the translation is of a good quality and that it is able to perform its function. Consequently, the need of translation assessment has appeared and a new scientific branch was born, i. e. translation science. Translation science defines terms, sets criteria for assessment, educates translators and interpreters etc.

\section{WHAT IS TRANSLATING?}

Translating is mostly defined as saying or writing something in a different language or expressing something in a different way, using a different system or alphabet.

A text, which is being translated, is called a source text. A language of the source text is called a source language, the language into which the text is being translated is called a target language. Said in another way: translating is conversion from source (L1) into target (L2) language. The person, who is translating, is called a translator. Translating into a foreign language is called decoding, translating into a mother tongue is called encoding. The product of translating is translation.

\section{THE HISTORY OF TRANSLATION}

The need of translating appeared together with the creation of a text; Cicero and Hieronymus are most known translator pioneers. However, scientific research of translation is relatively new. It is now under the leadership of FIT (FedérationInternationale des Traducteurs ), which is devoted to researching the history of translation. They put most attention to an author's contribution to intellectual and cultural history. They are interested in written and spoken translation; who the author is, what is translated, social and political context etc.

Most recent approaches are triple:

- according to geographical and cultural units, where the history of translation is researched regarding individual cultures and traditions in certain periods (e. g. European tradition in renaissance);

- according to national units (e. g. Slovenian tradition);

- researching different translations of the same work and author (e. g. translation of Bible in different cultures; translation of Shakespeare in different languages ).

There have been some doubts about the purpose of such research and its method. Furthermore, there have been some dilemmas about the word history; historiography and historiology have also been used. Regardless of this, there are more and more articles, debates, monographies and other works, dedicated to the history of translation, which is becoming independent and self-sufficient branch of research.

\section{WAYS OF TRANSLATING}

There are three ways of translating:

close translation,

free translation and

machine-aided translation.

Close translation is word for word translation; the unit of translation is a word or a phrase and the translator tries to translate it with as little adaptation as possible. Close translation is possible only when source and target languages belong to the same language group, when they have similar cultural backgrounds, and when language structures and thought concepts are close. Close translation is impossible when the meaning of the source text is changed, when it is structurally impossible, does not express any objective or thought concept in the target language, or the translation belongs to another register.

Free translation is diametric to close translation. It is used for translating bigger language units, like clauses, sentences, or paragraphs, which become the units of translation. The translator translates their meaning.

Machine-aided translating refers to the use of language 
technologies, such as electronic dictionaries and translation software. The latter enables faster, more efficient and better quality translating. It does not mean that the translation is done automatically; it only provides some help.

Two of the translation tools are Wordfast in Trados; they provide partial automatization of translation process, but only after words / phrases / sentences have already been translated and stored into programme's corpora by the translator. The advantage is that the translator does not need to translate the same words / phrases / sentences more than once. It is an excellent aid in legal, technical, business etc. translating, which demand consistency and unambiguousness.

\section{TYPES OF TRANSLATING}

5.1 There are different types of translating:

\section{interpreting,}

literary translation,

scientific-technical translation, subtitling.

5.2 Interpreting is oral conversion into target language.

A person doing interpreting is called an interpreter.

Languages, known by the interpreter, are:

- A language, which is an interpreter's mother tongue,

- B language) is an interpreter's foreign language of which an interpreter has an active knowledge and

- C language, of which an interpreter has a passive knowledge.

An interpreter translates into languages $\mathrm{A}$ and $\mathrm{B}$ and from languages A, B and C.

\subsubsection{Modes of interpreting:}

- consecutive interpreting, where an interpreter stands by speaker's side and is translating in sections;

- simultaneous interpreting, where an interpreter translates from the cabin, while the listener wears earphones and hears only translation;

- whispering (whispered interpreting, chuchotage) is used only when a maximum of three people do not understand the source language. An interpreter is present with the client and translates using whisper, with no devices. There are at least two drawbacks to whispered interpreting: it is very burdening for the interpreter's vocal cords and the client might have problems hearing interpreter's speech;

- sign language interpreting is for people with hearing problems.

5.2.2 Mona Baker distinguishes the following types of interpreting:

- community interpreting,

- legal interpreting or court interpreting,
- conference interpreting,

- business interpreting,

- technical interpreting,

- dubbing.

Community interpreting is used in public facilities, such as police, social services, customs, medical centres, immigration services etc. It is usually consecutive and two-way. An interpreter is not only a translator, but also a social intermediary.

English terminology distinguishes precisely between legal and court interpreting; legal interpreting refers to all types of interpreting in legal procedures, such as questioning at the police and customs, interviews with a solicitor, public attorney etc. Court interpreting refers strictly to interpreting in the court of law.

Conference interpreting demands a group of interpreters, who are interpreting to participants of a conference, usually in multiple languages. It can be done in any mode of interpreting, but most common is simultaneous.

Business interpreting is used in business world, where different companies communicate with their clients etc.

Technical interpreting is very wide area of interpreting (mechanics, electronics, telecommunications, mobile technology etc.), which means that the interpreter must specialize in a certain area.

Dubbing is oral translation of television shows, where a source spoken text is substituted with the target language. Dubbed text tries to follow the source text regarding the length of speech, the use of words etc.

\subsubsection{Forms of interpreting}

Forms of interpreting are:

- face-to-face, liaison, ad-hoc interpreting,

- telephone interpreting, over-the-phone interpreting / OPI and

- Videoconference interpreting.

Face-to-face interpreting is interpreting when an interpreter is physically present with the client, who needs interpreting. In can be done in any mode and type. Since the competition is huge, new types of interpreting appear. One of more interesting ones is so called escort interpreting, where an interpreter escorts the client on the field, excursions, shopping, airports etc.

Telephone interpreting is done over the phone. Its advantages are lower costs, the possibility of rapid service and distance interpreting. It can be done simultaneously and consecutively.

Modern technology enables the use of internet. Interpreting done via internet (e. g. Skype) is called videoconference interpreting. The advantages are the lowest costs, the possibility of rapid service. The 
conversation is more authentic, because the speakers can see each other. Another advantage is that besides simultaneous and consecutive it enables sign interpreting.

5.2.4 Basic difference between translating and interpreting is that translation is done in a written form, while interpreting is done orally. Translators must have a great command of written language and interpreters of oral language. The difficulty of interpreting is facing with unknown, spontaneous dialogues in two languages. Since an interpreter must know the terminology of a certain area very well, they are specialized for smaller number of areas (e.g. medical interpreting, pedagogical interpreting etc.).

\subsection{Literary translation}

Literary translating is defined as translating literary works: poetry, prose, and drama. Literary translation means translating belletristic works only.

Literary translation has had a vital role since the Antiquity, although then it was limited to translating only the most important authors and works. Translation theory is more and more focused on intercultural conversion and less and less on linguistic analysis as such. A translator represents a bridge between two cultures. Translator's aim is to make a source text understandable to a reader in a target language. It is here that practical part of translating (so called practices) and theoretical part (so called translation theory) of translating clash. Today, besides excellent knowledge of source and target languages, literary translators are required to be familiar with literary history, literary theory, translation theory, and cultural history of linguistic communities from which and into which they are translating. The clash between two cultures is called interculturality.

\subsection{Scientific-technical translation}

Scientific-technical translation is a translation of scientific or technical text. The translator must be very consistent, precise, and must be familiar the area of his expertise very well. Style must be objective, unambiguous, unemotional, and clear. Thus long sentences and complicated clause structures should be avoided.

\subsection{Subtitling}

Subtitling is written translating of television shows. Written translation of speech is written at the bottom of the screen simultaneously with speech itself. Subtitles are written in two lines, one of which does not exceed 35 signs. Subtitles are centre or left aligned.

\section{CORPORA}

Corpora are extremely comprehensive collections of texts in electronic version. They provide information about a certain language with the use of special software called concordancer; concordancing programme. Baker (2001) names three types of corpora: parallel (text A together with its translation), multi-lingual (similar monolingual texts in source languages with no translations provided; texts are chosen according to set criteria); comparative (source and translated texts in one language).Development of lexical corpora began with the development of computers, mostly in English speaking countries. In 1987 the first monolingual English dictionary, based entirely on lexical corpora, was published (Collins Cobuild). United Kingdom founded BNC (British National Corpus), which is the collection of more that hundred million words. Terminology banks are the collection of words from various professional areas. They are mostly electronic. Disadvantage is that they do not provide translations into foreign languages, but only definitions and examples of use. European Union has more such terminology banks, e.g. Euroterm (legal expressions) etc. Web corpora are mostly freely accessible, but majority of them (including Euroterm) is not adapted to the use of professional translators.

\section{TRANSLATION ORGANIZATIONS}

There are more institutions, societies and organizations, which deal with translation. International Standing Conference of University Institutes of Translators and Interpreters, abbreviated as CIUTI, is an international academy associating translation and interpretation institutes affiliated to universities. Founded in the 1960s, the institution aims at promoting international T\&I cooperation in both professional training and academic research. The establishment of CIUTI was proposed by the universities of Geneva, Heidelberg, Mainz/Germersheim, Paris-Sorbonne, Saarbrücken and Trieste, in response to the high demand for competent translators and interpreters after World War II. The CIUTI membership is open to institutions at the level of tertiary education only, and restricted to those who offer programs in translation, interpreting and multilingual communication. A set of high quality standards is attached to membership applications, which involves strict requirements on curriculum structure, research, academic infrastructure and resources of applicant institutions.

European Masters in Conference Interpreting, abbreviated EMCI, is an organization for conference interpreting training at advanced (postgraduate) level provided by a consortium of European universities in collaboration with the European Commission and the European Parliament. 
The EMCI programme is designed for students with European and non-European languages. The member institutions pursue a common policy on student recruitment and assessment and are committed to quality maintenance and regular reviews of the programme to adapt to changing needs and new developments. The EMCI Consortium underwent a complete reform in 201112 and became the EMCI Consortium II.

EULITA, the European Legal Interpreters and Translators Association, was founded in Antwerp, Belgium, in 2009. It is a non-profit association, established under the Criminal Justice Programme of the EU Commission's Directorate-General of Freedom, Security and Justice.

FIT (FédérationInternationale des Traducteurs / International Federation of Translators) is an international grouping of associations of translators, interpreters and terminologists. More than 100 professional associations and training institutes are affiliated, representing more than 80,000 translators in 55 countries. The goal of the Federation is to promote professionalism in the disciplines it represents.

In 1991 FIT launched the idea of an officially recognized International Translation Day to show solidarity of the worldwide translation community in an effort to promote the translation profession in different countries. International Translation Day is celebrated every year on 30 September on the feast of St. Jerome, the Bible translator who is considered the patron saint of translators. This day is an opportunity to display pride in a profession that is becoming increasingly essential in the era of progressing globalization.

CEATL is an international non-profit association under Belgian law, officially created in 1993 as a platform where literary translators' associations from different European countries could exchange views and information, and join forces to improve status and working conditions of literary translators. Set up by 10 founder members, CEATL now has 35 member associations from 29 countries across Europe, representing some 10,000 individual authors.

CEATL has two sets of aims, one internal and one external. On the internal front they gather information on the situation of literary translation and translators in the member countries and share experiences and examples of best practice. On the external front they defend the legal, social and economic interests of literary translators in a European context, which includes EU lobbying and reacting publicly to trends or events impacting on our profession and on the quality of literary translation. They help individual member associations to strengthen the position of literary translators in their countries.

\section{TRANSLATION STUDIES}

Translation studies is an academic discipline, which studies translation in the broader sense of the word. This includes all types and modes of translation. Translation studies involve a huge range of research and pedagogical activities (mentorships to future translators, studies, education etc.), preparation of theoretical guidelines for translation assessment etc.

Translation studies is a relatively new branch of science. It has been active since approximately 1970. James Holmes (1970) was the first who prepared an in-depth overview of activities within translation studies. He divided translation studies into two branches: pure translation studies and applied translation studies. Pure translation studies has two goals: descriptive and theoretical.

In descriptive translation studies he distinguishes: product-oriented translation studies (assessment and description of existent translations), process-oriented translation studies (analysis of mental activities in progress during translation process), and functionoriented translation studies (analysis of the function, which is performed by the translation in the target culture).

In theoretical translation studies he distinguishes general translation studies and partial translation studies. Partial translation studies are further divided into mediumrestricted translations (analysis of translation regarding who/what is translating - a person or a computer, whether it is done orally or in writing etc.), area restricted translation (analysis of trans lation considering specifics of certain groups, e. g. cultural and/or linguistic groups), text-type restricted translation (analysis of translation regarding genre, forms etc.), time restricted translation (analysis of translating regarding when it was made), and problem restricted translation (analysis of specific themes, e.g. translation of metaphor).

He divides applied translation studies into translator training (education of translators), translation aids (dictionaries, corpora, terminological corpora etc.), and translation criticism (as sessment of translation).

Toury (1995) wrote a similar overview, but unlike Homes he does not regard applied translation studies as equivalent discipline within translation studies, but only as subsidiary discipline

\section{TRANSLATAB ILITY}

Translatability or untranslatability is a concept, which describes what is translatable, what is untranslatable, when, how, and where certain concepts become untranslatable. It creates new areas of decisions and principles, opens new ways of solving practical problems and offers new approaches to discussions about 
theoretical themes. There are no unified criteria to what is translatable or untranslatable; it is a decision based upon discussions and research. The aim (function) of the source and target texts is likewise of vital importance. Translatability is usually explained regarding the relationship between source and target texts and the meaning expressed in both. The term describes the capability of conversion of a certain meaning from source to target language without any significant changes. In this regard there are three approaches to translatability. The first is rationalistic, which claims that the ideas are universal and thus translatable into every language. Relativistic theories claim that ideas are untranslatable into other languages, because the meaning and verbalisation are too closely connected. Other authors (e.g. Grosman, Jakobson) claim that it depends on the target culture; according to them it is difficult or impossible to translate the notions, which are little known or unknown in the target culture. Grosman also points out that it is important to keep in mind that words have different connotations in different cultures. E. g., a word democracy has various constellations of meaning, which depend on location and time of use and cultural space.

\section{CONCLUSION}

The article skims briefly through the main points of translation science and does not offer an in-depth discussion of any points. It provides some basic starter information for those interested in studying translation.

\section{REFERENCES}

[1] Baker, M. (2001). Routledge Encyclopedia of Translation Studies. London, New York: Routlege.

[2] Holmes, James S. et al., (ed.) (1970). The Nature of Translation. Essays on the Theory and Practice of Literary Translation. Bratislava: L'Aja.

[3] Grosman, M. (2004). Književnost v medkulturnempoložaju. Ljubljana: Znanstveniinštitut Filozofskefakultete.

[4] Toury, G. (1995). Descriptive Translation Studies And Beyond. Philadelphia: J. Benjamins.

[5] Gabrovšek, D.,"Prevajalstvo, slovarstvo in jezikoslovje," in PRISPEVKI k tehniki prevajanja iz slovenščine $\mathrm{v}$ angleščino: teorija in praksas lovenskoangleškekontrastivneanalize, S.Klinar, ed. Radovljica: Didakta, 1996, pp. 9-12.

[6] Phelan, M. (2001). The Interpreter's Resource. Clevdon: Cornwell Press.

[7] CIUTI. https://en.wikipedia.org/wiki/CIUTI

[8] EMCI. http://www.emcinterpreting.org/

[9] EULITA. https://eulita.eu/wp/

[10] FIT. http://fiz-ift.org

[11] CEATL. www.ceatl.eu 